\title{
Patient and surgeon factors associated with postoperative kyphosis after laminoplasty
}

\author{
Authors Joshua Ellwitz ${ }^{1}$, Rolando Roberto ${ }^{2}$, Munish Gupta $^{2}$, Vivek Mohan ${ }^{3}$, Eric Klineberg ${ }^{2}$ \\ Institutions $\quad{ }^{1}$ HCMW Spine and Scoliosis Center, Kalamazoo, Michigan, USA \\ ${ }^{2}$ UC Davis Medical Center, Sacramento, California, USA \\ ${ }^{3}$ Complete Orthopaedic Care, Lincolnshire, Illinois, USA
}

\section{INTRODUCTION}

Expansive cervical laminoplasty began its evolution in the 1970s in Japan for the treatment of cervical spondylotic myelopathy secondary to ossification of posterior longitudinal ligament or cervical spondylosis. The goal of the procedure is to reduce the complications associated with the inherent destabilization associated with laminectomy while preserving cervical spine range of motion [1].

It has also been established in the literature that preoperative kyphotic deformity is a risk factor for poor surgical outcome and neurological recovery [2,3]. We hypothesize that meticulous preservation of the interspinous ligaments may help prevent iatrogenic kyphosis.

\section{METHODS}

A retrospective review was conducted of patients who underwent laminoplasty from 2003 through January 2011 at UC-Davis Medical Center in Sacramento, Calif, USA. Patients who had simultaneous or staged anterior fusion in addition to laminoplasty were excluded. Additional exclusion criteria were inadequate preoperative or 3-month postoperative x-rays. Cervical lordosis was measured on preoperative, 3-month postoperative, and l-year postoperative (when available) x-rays. Additional data collected include patient age, surgeon performing the procedure, and preoperative/postoperative Nurick scores. There were technical differences that were surgeon dependent and are illustrated in Table 1. Statistical analysis was performed.

\section{RESULTS}

Fifty-seven people met inclusion criteria and had presurgery and 3-month postsurgery cervical x-rays. Of the 57 patients, 32 also had postsurgery x-rays at 12 months. The average age of patients was 58.4 years $(\mathrm{SD}=13.3$ years), and the average presurgery Nurick score was $1.7(\mathrm{SD}=1.5)$. There were 3 surgical techniques used: surgeon $1(n=21)$, surgeon $2(n=15)$, and surgeon $3(n=21)$ (Table 1).

The average cervical lordosis measured was the following: presurgery, $8.4(\mathrm{SD}=11.9)$; at 3 months, 4.0 ( $\mathrm{SD}=13.2)$; and at 12 months, $4.8(\mathrm{SD}=15.2)$. The average change in cervical lordosis measured presurgery to 3 months postsurgery was $-4.4(\mathrm{SD}=9.7)$ and the average additional change in cervical lordosis measured from 3 months to 12 months postsurgery was -0.38 ( $\mathrm{SD}=5.8)$ ( Fig 1). 


\section{CONCLUSIONS}

Preventing kyphosis after laminoplasty allows decompression of the spinal cord by allowing it to float posteriorly due to the enlarged spinal canal. Decreased surgical outcomes have been observed when cervical kyphosis is more than $13^{\circ}$ without cord signal change and more than $5^{\circ}$ when cord signal change is present [3]. Our study demonstrates that the use of a plate for stabilization and meticulous preservation of the interspinous ligaments limits postoperative kyphosis. Additionally, the best predictor of postoperative sagittal alignment is preoperative sagittal alignment and the change in alignment is independent of the preoperative alignment.

\section{REFERENCES}

1. Subramaniam V, Chamberlain RH, Theodore $\mathbf{N}$, et al (2009) Biomechanical effects of laminoplasty versus laminectomy: stenosis and stability. Spine (Phila Pa 1976); 34:E573-578.

2. Ratliff JK, Cooper PR (2003) Cervical laminoplasty: a critical review. J Neurosurg; 98(suppl 3):230-238.

3. Suda K, Abumi K, Ito M, et al (2003) Local kyphosis reduces surgical outcomes of expansive open-door laminoplasty for cervical spondylotic myelopathy. Spine (Phila $\mathrm{Pa}$ 1976); 28(12):1258-1262.
Table 1 Surgical technique by surgeon.

\begin{tabular}{lll}
\hline Surgeon & Fixation & $\begin{array}{l}\text { Interspinous } \\
\text { ligaments }\end{array}$ \\
\hline 1 & Plate and allograft & Variably preserved \\
\hline 2 & Plate and allograft & Meticulously preserved \\
\hline 3 & Suture anchor & Not preserved \\
\hline
\end{tabular}

Table 2 Estimates of cervical lordosis measures and the variation in change among surgeons.

\begin{tabular}{|c|c|c|c|c|}
\hline Parameter & Estimate & $\begin{array}{l}\text { Confidence } \\
\text { interval }\end{array}$ & $P$ value & $\begin{array}{l}\text { Total } \\
P \text { value }\end{array}$ \\
\hline $\begin{array}{l}\text { Average change in lordosis, } \\
3 \text { mo after surgery for surgeon } 1\end{array}$ & -3.71 & $-7.5,0.1$ & .06 & \multirow{3}{*}{$<.01$} \\
\hline $\begin{array}{l}\text { Average change in lordosis, } \\
3 \text { mo after surgery for surgeon } 2\end{array}$ & -1.33 & $-5.9,3.2$ & .56 & \\
\hline $\begin{array}{l}\text { Average change in lordosis, } \\
3 \text { mo after surgery for surgeon } 3\end{array}$ & -7.19 & $-11.0,-3.4$ & $<.01$ & \\
\hline
\end{tabular}

Fig 1 Scatter plots of preoperative lordosis measures versus the change at 3-month postoperatively (left), preoperative lordosis measures versus the additional change between 3 and 12 months postoperative (middle), and the change in lordosis at 3-months versus the change in lordosis at 12-month postoperatively (right).

Preop vs $3 \mathrm{~m}$ change in lordosis measures

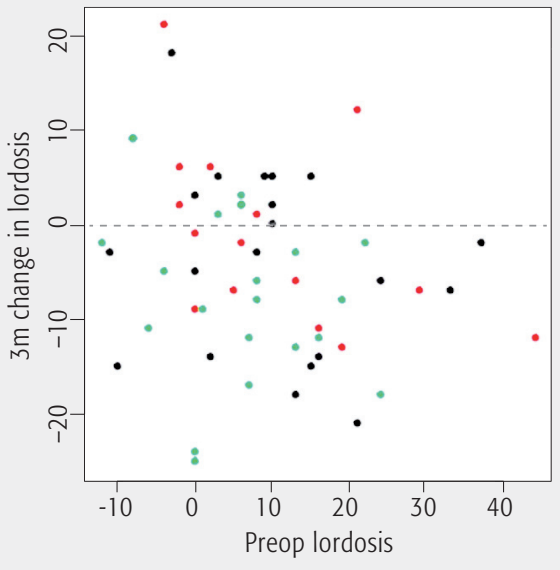

Preop vs additional change at $12 \mathrm{~m}$

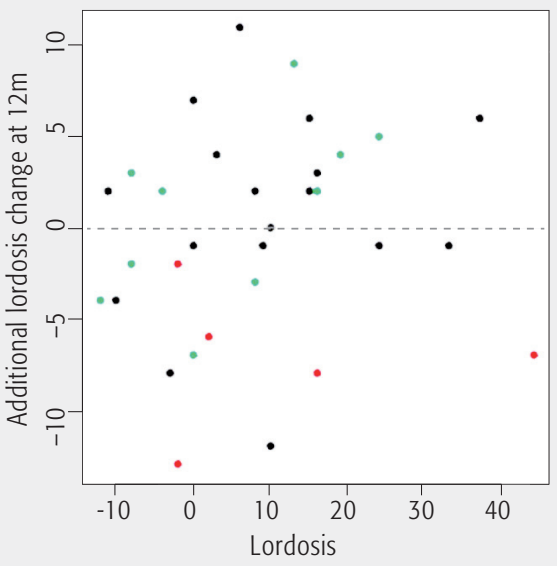

Change at $3 \mathrm{~m}$ vs additional change at $12 \mathrm{~m}$

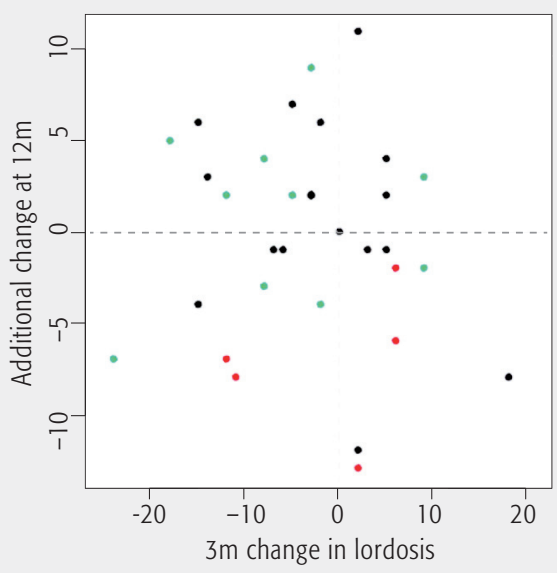

